\section{A codificação moral da medicina: avanços e desafios na formação dos médicos}

\section{Producing a moral code for medicine: advances and challenges in medical training}

Roberto Luiz d'Avila 1
1 Programa de Doutoramento em Bioética. Faculdade de Medicina. Universidade do Porto. Alameda Prof. Hernâni Monteiro, 4200319. Porto, Portugal. E-mail: roberto@cfm.org.br

\begin{abstract}
The aim of this article is to discuss how the moral code for medicine is produced and to demonstrate the need for technical training to be expanded to include humanitarian features. To this end, it first addresses medicine as a science and as an art founded on moral principles. Then, it reviews the historical context of the production of the moral codes for medicine, with a specific focus on Brazil. Finally, it discusses the prevailing medical code, pointing out the importance of not regarding it as a strictly punitive tool, but as a set of guidelines for the promotion of the well-being of patients and the improvement of society in general. It concludes by indicating the need for medical schools to go beyond technical training and provide on-going preparation for dealing with humanitarian issues, thereby developing the sense of morality among the students and future doctors.
\end{abstract}

Key words Bioethics, Ethic, Morale, Medicine

\section{Resumo}

O presente artigo objetivou discutir a codificação moral da prática médica, mostrando a necessidade de ampliar a formação tecnicista com elementos humanitários. Neste sentido, abordou primeiramente a Medicina como ciência e arte pautada em princípios morais. Posteriormente, revisou o contexto histórico da codificação moral médica, enfocando a realidade brasileira. Por fim, discutiu-se o código médico vigente, destacando a importância de não considerálo como ferramenta estritamente punitiva, mas de orientação para a promoção do bem-estar dos pacientes e melhoria da sociedade. Concluindo, indicou-se a necessidade de as escolas médicas oferecerem, além de formação técnica, uma preparação contínua em temas humanitários, promovendo o desenvolvimento moral dos estudantes e futuros médicos.

Palavras-chave Bioética, Ética, Moral, Medicina 


\section{Introdução}

A moral e a ética são dois conceitos estreitamente relacionados. Do latim mores, moral significa "relativo aos costumes"; etimologicamente, a palavra moral teve origem na tentativa dos romanos de traduzirem a palavra grega êthica. Contudo, esta não é satisfatoriamente traduzida; para os gregos êthica possuía dois sentidos complementares: o primeiro derivava de êthos, significando a interioridade do ato humano, aquilo que gera uma ação genuinamente humana e que brota a partir de dentro do sujeito moral (o âmago do agir, o sentido da intenção). Por outro lado, êthica significava também éthos, indicando a questão dos hábitos, costumes, usos e regras, o que se materializa na assimilação social dos valores. ${ }^{1}$ Neste artigo, sem desconhecer o primeiro significado de êthica, assume-se o sentido mais restrito à éthos, compreendendo a moral como um conjunto de regras para o convívio.

O objetivo principal é mostrar como a medicina tem procurado sistematizar o éthos da prática médica, tratando de propor codificações da moral, como a que recentemente teve lugar por meio da Resolução CFM n ${ }^{\circ}$ 1.931/2009,2 representando uma resposta aos avanços científicos, tecnológicos e sociais registrados nos últimos anos, vistos sob a égide de princípios bioéticos sistematizados nas três últimas décadas. Com o fim de tornar clara a construção do éthos na medicina, demanda-se tratar algumas temáticas principais, como a prática médica como atividade moral, a história da codificação moral médica, com ênfase no contexto brasileiro, e a discussão acerca da ética-bioética e deontologia médica.

\section{A medicina como atividade moral}

A palavra Medicina, iniciada com letra maiúscula, diz respeito à ciência que tem como objetivos a preservação e a recuperação da saúde e a prevenção, o diagnóstico e a reabilitação de enfermos. Referese, ainda, ao curso superior desta ciência. No caso de empregá-la com a inicial minúscula, indica o ofício ou a profissão de médico.

Desde quando filósofos e médicos começaram a refletir criticamente sua natureza e propostas, a medicina se mostrou uma atividade moral reconhecida como tal. Isso levou a um renascimento da ética médica e iniciou-se uma integração entre a prática clínica e a disciplina intelectual formal. A escolha, pelo médico, dentre muitas coisas que podem ser feitas ao paciente, do ponto de vista técnico, e aquelas que devem ser feitas, em uma determinada circunstância clínica, é um problema ético, e deverá ser, sempre, a decisão certa e melhor para o paciente. 3

Galeno (131-200), médico e filósofo grego que distinguiu os nervos sensoriais dos motores e descreveu o coração, ressaltava que para ser um bom médico era necessário ser, também, filósofo, afirmando que a ética médica consiste em aplicar a ética geral ao domínio da medicina; e Hipócrates estabeleceu que o médico deve considerar sempre o particular e que a determinação das características dos indivíduos se dá por meio da sensibilidade, opinando que o médico, seguramente, contraria o enfermo e dobra sua vontade ao administrar-lhe o necessário, porém necessita de sua colaboração. ${ }^{4}$ Porém, a tradição das escolas médicas tem enfatizado o conhecimento científico em detrimento da formação moral, não se podendo esquecer que da essência da medicina fazem parte o sofrimento e a dor, a angústia e a morte, exigindo daquele que a exerce não somente perícia e técnica, mas também qualidades pessoais como zelo, temperança e honestidade. As competências técnica e ética não se bifurcam, ao contrário, caminham lado a lado na formação do médico. 5

Nascida da beneficência, o primeiro princípio a se estabelecer entre os homens, a medicina surgiu da necessidade de ajuda e cuidado de um para com o outro ser humano. Necessidade esta caracterizada quando alguém sentiu dor e pela primeira vez outro ser humano, impregnado pelos sentimentos de compaixão e beneficência, ficou ao seu lado. Não foi necessária a cura, bastando somente a presença e o cuidado. É meridiano verificar que dois dos quatro princípios consagrados na bioética principialista 6 (beneficência e não-maleficência) são hipocráticos, constando, inclusive, do próprio Juramento de Hipócrates, introduzido pelo Papa Clemente VII, em 1531, na bula Quod jusiurandum, que o prescrevia a todos que obtinham o grau em medicina. 7

A medicina é ciência (no sentido popperiano, um conhecimento sistemático, objetivo e pautado em evidências empíricas refutáveis) e arte (compreende uma technê, e não uma prática sem regras, fundada apenas sobre o reclamo, a gritaria e as receitas de charlatães; é uma técnica adquirida, organizada e eficiente, da qual somente os práticos qualificados são os verdadeiros depositários). Porém, nos primórdios, esta disciplina era mais arte do que ciência; o médico tinha uma sensibilidade hipertrofiada, já que os recursos diagnósticos e o arsenal terapêutico eram tão parcos quanto os conhecimentos científicos da época. Hoje, sendo reconhecida epistemologicamente como ciência, a medicina necessita de 
conhecimentos técnicos específicos calcados em metodologia científica e, por ser arte, requer um modo de conduta moral, pautadas em virtudes, ao fazer as intervenções em seu sujeito de trabalho: o ser humano. Por isso, tem um caráter relacional mediador de desejos, paixões e afetos. As normas de conduta, baseadas em princípios e valores, sustentam este caráter relacional, fazendo com que a interação médico-paciente se revista do mais elevado cunho ético-moral e ao mesmo tempo seja fonte de tantos conflitos no exercício da arte de aliviar dores e consolar. 8

Em razão do que se comentou, quando do ato médico resulta dano, perde-se o atavismo contido na prática médica de fazer o bem. A maleficência, embora não intencional, é a antítese da arte e da ciência e, por isso, a sociedade reage tão pouco condescendente contra os autores do malfadado dano. Quando do ato de fazer o bem resulta o mal, é comum reagir com indignação. Porém, a indignação não é menor quando apenas a ciência médica é cultivada. Somente o conhecimento científico e a aplicação dos recursos técnicos no diagnóstico e na terapêutica não tornam o médico melhor $\mathrm{e}$, tampouco, a medicina mais humana. $\mathrm{O}$ bom médico necessita de outras habilidades além do conhecimento científico, como: intuição, bom senso, capacidade de julgamento moral de suas ações e amor ao ser humano.

A medicina, nos dias de hoje, apenas tem sentido se seu entendimento e suas atividades estiverem em um contexto moral. Seu papel moral encontra-se, no mundo hodierno, em discutir as limitações da tecnologia, dos recursos e da condição humana, alertando para a chamada introspecção pós-moderna da filosofia contemporânea. Neste ponto, entende-se que toda questão ética deve ser vista, sempre, como um julgamento moral, em sua forma mais superficial entendida como uma reflexão sobre a moralidade de uma determinada ação. Tais julgamentos morais podem e devem ser justificados, pois obedecem a regulamentos ou normas, e estes são baseados em princípios. Além disso, esse conjunto de princípios pode ser sistematizado em teorias ou modelos pedagógicos.

A partir da metade do século passado, surgiram alguns complicadores da relação médico-paciente, destacando-se a tecnologia, a super-especialização, a interposição institucional e o papel dos meios de comunicação. ${ }^{9}$ Assim, a tecnologia tirou o médico da cabeceira de seu paciente, fazendo com que a mão que sentia, tocava, percutia e confortava fosse substituída por visores luminosos e sonoros, por aparelhagem cada vez mais sofisticada. O calor humano do profissional tornou-se mais distante e a cibernética desprezou o contato mais próximo e atento do médico. De fato, os avanços científicos e tecnológicos trouxeram diversos questionamentos, sobretudo no campo humanitário, impondo um conflito entre aquilo que é possível fazer (e a tecnologia permite) e o que deve ser feito (a ética e a bioética recomendam). Não há dúvida de que esses avanços dispensam argumentação, mas também não há discordância de que há uma franca deterioração dos padrões éticos na prestação dos serviços médicos, isto é, tem-se ganhado em tecnologia e perdido em humanismo.

É notório nos dias de hoje a propaganda e a publicidade utilizarem imagens e textos valorizando a estrutura física e a hotelaria ou a tecnologia na assistência à saúde. Se comparada a publicidade de um famoso hospital de São Paulo, há dez anos, verifica-se ser este o tema principal deste hospital, indicando a instituição como símbolo de tecnologia e alta qualidade. Tal concepção publicitária vem se modificando e a mais recente publicidade, desse mesmo hospital, mostra, com menor destaque, a tecnologia, focalizando, com a devida importância, a relação médico-paciente e, em especial, dando relevância ao toque de mãos nesta relação, representando o cuidado. Quiçá, fruto de reflexões que cada dia mais são realizadas, denunciando o tecnicismo e o descuido com as relações interpessoais. 8,9

Os ganhos em tecnologia contabilizaram perdas em contato humano e poucos médicos têm, hoje em dia, tempo para ouvir seus pacientes, perscrutar seus sentimentos, perquirir suas dores, entender seus sofrimentos, auscultar seus corações e apalpar seus corpos físicos. Ao afastar-se da arte de ouvir e examinar os pacientes deixou o médico de ser médico, transformando-se em "técnico em medicina". Possivelmente, a credibilidade nos médicos tem diminuído, aumentando proporcionalmente o número de denúncias. 10 Assim, mais médicos comparecem à justiça comum e notícias nos jornais questionando atitudes médicas tornaram-se manchetes desfavoráveis. Entretanto, a culpa (se há alguma) não pertence, isoladamente, aos médicos e, tampouco, ao aparelho formador. A descrença das pessoas quanto à competência do profissional, acreditando mais nos resultados de testes e exames laboratoriais desvaloriza a arte da anamnese e do exame físico.

Uma sociedade que exige do Estado o cumprimento do preceito constitucional de que a saúde é dever do Estado e direito do cidadão, deveria preocupar-se com as condições indignas de trabalho às quais muitos médicos estão submetidos e, 
também, com a remuneração injusta do sistema público de saúde que caracteriza a importância que esta sociedade confere ao médico: 8,10 sua desvalorização. O médico deveria ter o reconhecimento pelos anos de estudo e investimento em sua formação e por ser, acima de tudo, a saúde reconhecida como o maior bem individual.

Este mesmo médico, na atualidade, é vítima do modelo estadunidense que apregoa o tecnicismo e a impessoalidade da relação contratual de meios que se estabelece entre ele e o paciente e, assim, afastase dos propósitos imutáveis que norteiam a relação médico-paciente: autonomia, verdade, esperança, cuidado e, se possível, a cura. A solidariedade e a sensibilidade são atributos essenciais para o médico, melhorando as relações com os pacientes, especialmente quando o enfermo compartilha com o seu médico os seus pensamentos, temores e segredos. Daí a importância desses atributos acrescidos de mais um atributo necessário: a compaixão. ${ }^{8}$ De tudo isso se depreende que o profissionalismo médico aspira competência profissional, mas também sinceridade, altruísmo, honra, responsabilidade, integridade e respeito pelos outros. ${ }^{7}$ Parece que tais atributos não são alcançados unicamente pelo aprendizado, mas aprimorado por ele, e o conjunto de traços morais que caracteriza a individualidade apresenta um cerne inato que pode ser aprimorado, mas que não é, na sua totalidade, produto da cultura.

No mundo globalizado de hoje, havendo diferentes opiniões no encontro entre médicos e pacientes, não existe uma visão unânime do bem comum e a influência do ambiente cultural, particularmente o familiar, é determinante na estruturação da personalidade, podendo haver reflexão para o enriquecimento de princípios éticos. Ao ser humano é permitida grande variedade de opções e opiniões, dependentes não só do ambiente cultural, mas, também, de influências psicológicas individuais, embora as decisões não sejam, isoladamente, o resultado de introspecções ascéticas, porém consequência de interações psicossociológicas. ${ }^{11}$

Cabem neste ponto algumas indagações: existiria uma capacidade inata de sentir compaixão? A educação médica, isoladamente, seria suficiente para formar o caráter do estudante de medicina? Compaixão, respeito, solidariedade e sensibilidade são qualidades eminentemente adquiridas? Elas podem ser aprimorados pela cultura? É certo afirmar que o comportamento das pessoas depende de suas experiências dentro da própria cultura, mas o conjunto de suas possibilidades é herdado? Estas perguntas se resumem à dicotomia ancestral inatoaprendido, que ninguém hoje se atreve a desprezar qualquer uma das duas alternativas. Possivelmente, parte importante dos sentimentos primários e mais nobres (e perversos) dos seres humanos é inata; porém, a educação pode fazer despertá-los ou inibilos, ${ }^{8,12,13}$ e o Estado, ${ }^{14}$ por meio de normas, leis, códigos e instituições 15,16 disciplina sua manifestação e a consequente prática profissional condizente com os anseios da população.

\section{Elementos da história da codificação da moral médica}

A medicina, como atividade profissional, sempre foi acompanhada, historicamente, de grande preocupação com a conduta moral dos médicos. Muito antes do juramento de Hipócrates, 7 diversas sociedades já tinham codificado a conduta recomendável dos médicos. Estes "códigos" eram bastante rigorosos para com os infratores, confundindo-se normas morais com normas penais. Mas, na Antiguidade o exercício da medicina era um aglomerado de mitos. Deuses curavam, como Asclépio fazia, por intermédio de sonhos em seu templo de Epidauro, na Grécia Antiga. Não se colocava em causa o insucesso dos médicos, mas levavam-se em consideração, apenas, as curas que, de tão raras, eram inscritas nas colunatas do templo. 12

Nessa época, os códigos de conduta médica associavam a prática da profissão com critérios mágicos e as doenças eram vistas como possessões demoníacas, não havendo uma ética propriamente dita, por falta de vínculo específico entre o médico e o paciente. Havia uma ligação da medicina com a religiosidade, pois o ofício emanava dos deuses e era exercido por homens veneráveis e ungidos pela fortuna da descendência. ${ }^{17}$

Séculos antes de Cristo, Hammourabi (primeiro imperador babilônico - 1810-1750 a.c., famoso por ter mandado compilar o mais antigo código de leis escritas) inscreveu diversas normas aplicadas aos médicos em seu famoso código, com a justa previsão de penas para aqueles incompetentes ou desastrados. ${ }^{18}$ A propósito, o artigo 218 do código de Hammourabi preconizava o seguinte: Se um médico trata de alguém de uma grave ferida com a lanceta de bronze e o mata ou lhe abre uma incisão com a lanceta de bronze e o olho fica perdido, se the deverão cortar as mãos. ${ }^{19}$ Nesta mesma linha, o livro de Hermes-Toth, do antigo Egito, condenava à morte os médicos que desrespeitavam as normas ali contidas. Na Índia antiga, o Código de Manú estabelecia castigos aos médicos faltosos. Portanto, a preocupação de punir os médicos não é recente, pois 
entre os ancestrais egípcios, gregos e romanos e, também, na idade média, já se faziam notar castigos destinados aos médicos faltosos.

A codificação moral da profissão médica ganhou maioridade com Hipócrates de Cós que, por meio de cento e vinte obras escritas há quatrocentos anos antes de Cristo, enfatizou o compromisso do médico em assumir a fidelidade às tradições da profissão. Em Roma, as leis sobre o erro médico eram tão severas que afastaram da profissão os mais capazes e os mais aptos, com receio de punições. Neste caso, houve a necessidade de importar médicos de Alexandria e Grécia. Depois, as leis repressivas foram caindo em desuso e a medicina passou por uma fase de prática descontrolada e indiscriminada, cheia de impunidade. 15

Hipócrates, cujo juramento (feito por todos os médicos ao concluírem o curso de graduação) fundamenta os códigos de conduta da profissão médica até os dias de hoje, emancipou a medicina da religião, inserindo-a no "reino" das ciências naturais e recordando aos médicos que seu trabalho consiste em fazer o bem em níveis vigilantes de responsabilidade, sacrifício e generosidade. Esta concepção é recorrente mesmo na atualidade, reconhecendo-se que a vida é o bem supremo e essencial, acima de qualquer outro princípio, sendo a saúde e sua conservação direitos contemplados e garantidos em constituições de vários países. 20

$\mathrm{O}$ velho mestre da ilha grega de Cós deixou a todos o sábio princípio médico: "primum non nocere", lembrando aos médicos o dever de considerar o bem-estar do paciente acima do seu próprio, o que se configura em obrigação fiduciária entre o médico e o paciente, evitando usar qualquer prática que resulte em dor e sofrimento para este. ${ }^{21}$ Foi o mesmo Hipócrates quem inseriu os critérios éticos na medicina, estabelecendo as obrigações do médico: o segredo profissional; a moderação nos honorários; o respeito aos colegas e mestres; e as proibições do aborto e da eutanásia, resguardando o médico e protegendo o paciente. ${ }^{7}$ Ele retirou o caráter mágico da medicina e codificou a deontologia médica por meio de seu juramento, dignificando a profissão pelo exercício do amor e da generosidade.

A medicina, como profissão regulamentada, teve início mesmo na Idade Medieval, com o surgimento das primeiras escolas médicas (século XII), fundamentadas na exigência de requisitos legais e acadêmicos para o seu exercício, assumindo um novo estatuto científico e social, havendo mudança da abordagem individualista para a social, no caso prevalecendo o interesse coletivo. Com a institu- cionalização da profissão e a consequente consciência e autoridade morais da medicina, adveio a deontologia, estabelecendo critérios próprios relativamente à moral comum, à religião e à lei.22

A partir do século $\mathrm{XV}$, começaram a surgir os primeiros tratados deontológicos, que tiveram como pioneiro o médico português, de origem judaica, Rodrigo de Castro (1542-1627). Em 1520, o Royal College of Physicians of London decidiu mudar a denominação do "Código Penal para Médicos" para "Código de Ética". O britânico Thomas Percival, em 1803, publicou a obra Medical Ethics: A code of institutes and precepts adapted to the professional conduct of physicians and surgeons, sendo reconhecido como o primeiro código de ética médica, por ser a obra que motivou outros países em anos subsequentes a estabelecerem seus próprios códigos de conduta para os médicos. A tendência a codificar os deveres médicos foi se fazendo cada dia mais presente e demandada, sobretudo quando mais organizada a profissão. Efetivamente, em alguns países houve incorporação dos deveres em normas jurídicas, especialmente àqueles de tradição jurídica romano-germânica. No caso do Reino Unido, observou-se total interdependência entre os princípios éticos e as normas jurídicas, tendo as associações profissionais a tarefa de divulgar os princípios da boa prática médica. Em Portugal, a base orientadora da conduta profissional foi estabelecida no atual Código Deontológico da Ordem dos Médicos, com ênfase na obediência de regras éticas independente de sua cominação legal.11 O que pode ter ocorrido no Brasil?

\section{A codificação da moral médica no Brasil}

Os primeiros médicos que chegaram ao Brasil datam do século XVI, por meio de expedições colonizadoras. Dentre eles é importante apontar o nome de Guilherme Piso, médico e naturalista holandês, considerado um dos pioneiros no exercício da medicina no país. Durante os sete anos que aqui passou dedicou-se às funções de naturalista, colecionando plantas e animais nativos, além de estudar a medicina, investigando formas de tratamento indígenas. Em 1648, já de volta à Holanda, publicou o trabalho De Medicina Brasiliensi, a primeira parte do tratado Historia Naturalis Brasilae, obra considerada o primeiro livro médico voltado especificamente ao Brasil. Este trabalho descreve os ares e as águas brasileiras, a evolução, reações orgânicas, tratamentos e efeitos de 22 moléstias endêmicas comuns, os venenos e seus antídotos e também as propriedades dos símplices. 23,24 
Além de casos excepcionais, como a vinda ao Brasil de Guilherme Piso, trazido ao país por Maurício de Nassau, até o século XVIII a medicina foi em sua maior parte exercida por barbeiros, cirurgiões-barbeiros, parteiras e físicos. Havia, naquela época, o cirurgião-mor ou físico-mor do reino que tinha poderes de fiscalizar e ditar normas sobre a saúde pública e o exercício da medicina. Eram concedidas, por Portugal, cartas ou diplomas de habilitação, o que permitia a licença para o exercício profissional. Já havia, então, a possibilidade de aplicação de penas como a suspensão ou multa contra os infratores. 16 Portanto, no Brasil da época colonial a preocupação principal era a habilitação profissional. Com a fundação das duas primeiras faculdades de medicina, ambas em 1808, na Bahia e no Rio de Janeiro, houve melhoria substancial no padrão de medicina exercida, com a chegada de médicos formados em faculdades européias e os que já começavam a ser formados no país.

Somente a partir da fundação das sociedades médicas, em meados do século XIX, foi possível um enfoque sobre a formação do médico e controle da abertura de novas escolas médicas. Porém, ao final da década de 1920, com o crescimento do movimento sindical, foi possível a implantação de um Código de Deontologia Médica, baseado no Código de Moral Médica aprovado no II Congresso Médico Latino-Americano, em Havana, em 1926. Em 1931, o Ministério da Educação e Saúde aprovou este código, outorgando o Conselho de Disciplina Profissional para "conhecer, julgar e sentenciar qualquer infração às disposições do presente Código".25 Os Conselhos de médicos foram criados na França em 1941, sendo acompanhados da elaboração do Código de Deontologia. Neste país, tal qual ocorre no Brasil, a intervenção do Estado é tradicional no que concerne à repressão penal. 14

Em 1945, no Brasil, o Decreto-Lei no 7.955 criou o Conselho Federal de Medicina provisório que não obteve o apoio da categoria por não representá-la. Em 30 de setembro de 1957, atendendo a principal reivindicação da classe médica e garantindo aos médicos o controle exclusivo sobre suas atividades, o Presidente Juscelino Kubitschek, também médico, criou os Conselhos Federal e Regionais de Medicina, por meio da Lei $\mathrm{n}^{\circ}$ 3.268. Então, tais Conselhos foram constituídos para executarem a missão estatal, sem vínculo com a administração pública, de tutelarem a sociedade coibindo eventuais práticas profissionais distorcidas. 26 Estes compreenderam órgãos representativos da classe médica, punindo os maus profissionais, agindo em conformidade com a lei: supervisionando, fiscalizando, normatizando e disci- plinando a atividade médica.

Neste país a produção de códigos de deontologia médica seguiu uma trajetória própria, numa matriz secular e filosófica, ${ }^{27}$ tendo todos os códigos um conteúdo moral que alinha dispositivos legais. Entretanto, nenhum documento desta natureza foi tão original como o Código de Havana, chamado de Código de Moral Médica, aprovado durante o II Congresso Médico Latino-Americano. Especificamente, define uma postura esperada dos pacientes diante dos médicos, destacando que os pacientes não devem importunar, causar delongas e prejuízos ao facultativo, devendo estar pronto, à hora certa, para o exame e não importunar o esculápio em horas impróprias, como o sono, as refeições e o lazer. O referido código indica, ainda, que o paciente deverá ser grato, pagar na hora certa, não atrasar o médico, ou seja, deverá ser o doente ideal.28

Em 1957 a Associação Médica Brasileira (AMB) elaborou o novo Código de Ética Médica, que vigorou até 1965 quando, então, o Conselho Federal de Medicina aprovou um novo código de ética como previa a Lei n ${ }^{\circ} 3.268 / 57$, com poucas alterações. Em 1984, outro código foi elaborado pelo Conselho Federal de Medicina, pressionado pelo desejo da categoria e impulsionado pela abertura política que se instalava no país. Após ampla discussão com a categoria profissional e outros segmentos da sociedade civil organizada, este Conselho aprovou, em 1988, o Código de Ética Médica que esteve em vigor até pouco tempo, dando lugar ao Código vigente a partir de 13 de abril de 2010. As mudanças principais incorporadas refletem conquistas de direitos, preocupações comerciais, avanços tecno-científicos e maior consciência de princípios bioéticos por parte da classe médica. Considerando os dois personagens principais, isto é, médicos e pacientes, tais mudanças podem ser agrupadas como seguem: 29

No caso dos médicos, os eixos temáticos principais abordados foram: a) relações comerciais: o médico foi impedido de participar em propaganda, ter relações com o comércio e as farmácias e fazer parte de sistema de desconto ou consórcio; b) condições de trabalho: é resguardado o direito ao sigilo e a recusa de trabalhar em condições precárias, mas não se admite sua falta em plantão; e c) desenvolvimento técnico-científico: é impedido de manipulação genética e escolha do sexo do bebê.

No caso dos pacientes, a ênfase maior foi assegurar a observância aos princípios bioéticos. Neste sentido, três eixos temáticos foram contemplados: a) justiça social: demanda-se que o médico tenha letra legível, inclua seu registro do Conselho Regional de Medicina nos documentos que expedir, possibili- 
tando uma segunda opinião profissional e não receitar sem ver o paciente; b) autonomia: direito de escolher terapia, entre as informadas, direito ao prontuário médico e escolha de método contraceptivo a usar; e c) não-maleficência: assinar consentimento informado, não ser abandonado e não se submeter a procedimentos desnecessários.

Portanto, como observado, os códigos têm se orientado em razão de demandas profissionais e da população. Não são invenções, mas tradução de normas e práticas sociais que têm funcionado, e inibição de outras que comprometem a atuação do médico e sua relação com o paciente. Mas, como é possível que este código não se restrinja ao papel, que oriente os profissionais e não apenas seja empregado para puni-los?

\section{Bioética, ética e deontologia médica}

Como ensinar ética médica e bioética? E como separar claramente a deontologia, e os respectivos deveres da conduta moral, que é imposta por meio de regras consensuadas e apoiadas em princípios e valores? Como construir a necessária reflexão ética sobre a moralidade dos atos médicos? São seguramente mais indagações do que se poderia imaginar em um primeiro momento, e o cerne das dúvidas parece ser um único ou principal: a competência das escolas de medicina para ensinar estas habilidades "secundárias", especialmente a viabilidade de elas promoverem o desenvolvimento moral dos acadêmicos.

Atualmente no Brasil se configura uma realidade médica algo angustiante. $O$ código de conduta ou comportamento moral vigente, embora tenha diminuído em 18,6\% o número de artigos com relação ao anterior, segue com mais de uma centena deles - são, especificamente 118. Seguramente, esta redução reflete uma mudança de perspectiva, assumindo princípios bioéticos, primando pelo que é melhor para o paciente e a sociedade, tratando de princípios mais universais que, espera-se, representarão uma promoção moral dos profissionais. Além disso, priorizando as condições de trabalho dos médicos, procurou inibir o afã comercial da medicina, coibindo atrelar os serviços médicos com interesses publicitários e farmacêuticos. Mas, se existem todas estas conquistas, é possível que o leitor esteja se perguntando: qual a angústia, então? As instituições representantes de classe se empenharam para oferecer o melhor código, mas a questão é saber como assegurar que ele não resulte simplesmente em maior incidência de punição em lugar de garantir melhor qualidade de saúde para todos.
A bioética aportou algo tarde em terras brasileiras, um atraso de aproximadamente duas décadas, ${ }^{6}$ considerando seu início em meados dos anos 1990. Apenas nos últimos anos estão sendo formados os primeiros doutores em bioética por programas de pós-graduação do Brasil ou que representem uma parceria com universidades estrangeiras. A incorporação da bioética principialista no Brasil começa a dar seus frutos evidentes, como o atual Código de Ética Médica. Esta abordagem teóricometodológica foi a que mais facilitou no cenário nacional a introdução de um pensamento reflexivo sobre justiça, beneficência, não-maleficência e autonomia, embora ainda reste muito para alcançar a autonomia anglo-saxã. E, sem dúvida alguma, o problema mais urgente e premente ainda é a questão do princípio de justiça, que traz embutida dois outros sub-princípios: igualdade e eqüidade. 30

Uma das características do ensino médico, no Brasil, é que a ética é uma disciplina ministrada sempre como deontologia, vinculada à medicina legal, com poucas horas de dedicação. São, geralmente, ensinados apenas os artigos e as condutas proibidas, uma vez que o Código de Ética Médica era até então (parte importante ainda segue sendo) majoritariamente proibitivo. Há pouco eram somente nove artigos que tratavam de direitos dos médicos; a maioria era restritiva, como se houvesse uma tendência inata do médico a praticar o ilícito e o código existisse para lembrá-lo. Análises mais detalhadas revelarão em que medida as mudanças no código atual contribuirão para resolver esta situação policialesca. Mas, o que parece evidente é que falta, tanto à bioética como à própria ética médica, um programa de ensino de forma hierarquizada, que atravesse todas as fases do curso médico, não se restringindo a uma disciplina de dois créditos (30 horas/aula). Muito provavelmente, contribuiria decisivamente ministrar permanente e transversalmente durante o curso conteúdos crescentes, não só em extensão, mas em profundidade; isso estimularia o desenvolvimento em lugar do retrocesso moral dos futuros médicos, que hoje carecem de conhecimento sobre temas humanitários; 18 o modelo médico corrente é biologicista, deixando de reconhecer que o homem não é só biologia, mas também biografia e símbolo.

Esta deficiência na formação ético-humanística no período de graduação, muito provavelmente, explica parte importante de descaminhos da conduta ética de alguns médicos. ${ }^{31}$ Este é um período crítico na vida dos jovens acadêmicos, propício para "moldar" ou dar direção ao seu caráter a partir da formação em valores e princípios essenciais, visando 
condutas orientadas por fundamentos universais, menos pautadas circunstancialmente, procurando assegurar o bem-estar do paciente e da sociedade como um todo. Parece haver suficiente acordo entre os professores de medicina de que a disciplina de ética médica deva fazer parte do currículo mínimo nos cursos de graduação; a dificuldade maior é estabelecer qual é o melhor período acadêmico para implantá-la.

No Brasil, na maioria das escolas médicas, quando presente, o ensino da deontologia médica concentra-se no último ano de curso $\left(8^{\circ}\right.$ e $9^{\circ}$ períodos), quando muitas decisões importantes na vida dos jovens já foram tomadas. Pesquisa de início dos anos 1990 indicou que das 79 escolas médicas à época, todas contavam com disciplina de ética, embora apenas $24 \%$ a concentravam nos três primeiros anos do curso. 32 Mas complicado ainda, existem casos em que o professor responsável não é exatamente um perito nesta temática, sobretudo pela ausência de formação específica no país, mas alguém deslocado para ministrar os conteúdos correspondentes.

Por fim, neste contexto a Comissão Interinstitucional Nacional de Avaliação do Ensino Médico (CINAEM), em seu relatório geral envolvendo os anos de 1991 a 1997, concluiu que o curso médico deve contemplar as dimensões biológica, psíquica e social do ser humano em sintonia com sua historicidade. Além disso, observou que a estrutura curricular era inadequada à realidade de saúde da população, oferecendo formação humanística deficiente, predominantemente tecno-cêntrica, com excesso de conteúdos teóricos. 33 Contudo, poucas escolas oferecem a disciplina de bioética, e algumas somente o fazem em determinadas fases, próximas ao fim do curso. Uma das exceções é a Universidade do Vale do Itajaí (Univale), localizada em Santa Catarina, onde a disciplina de bioética é apresentada ao longo de todo o curso, utilizando-se casos concretos e contando com a participação de juristas, teólogos e filósofos. Na maioria das vezes, porém, é dada ênfase apenas à deontologia, senso escasso conteúdo humanista e/ou uma disciplina de bioética.

\section{Considerações finais}

Vive-se na atualidade a angústia da necessidade de uma reformulação do ensino médico, não só da ética médica, mas, também, da introdução da bioética como matéria, para dar ao médico uma visão mais ampla do ser humano e colocar não só no professor, mas no estudante, a visão do papel social do médico e do médico cidadão, em nova construção de um pensamento médico moderno. As diretrizes curriculares, propostas pelo Ministério da Educação e Cultura, baseadas em trabalho no qual a Comissão Interinstitucional Nacional de Avaliação de Ensino Médico realizou, ao longo de 11 anos, ${ }^{31}$ deverão ser adotadas por todos os cursos, onde buscarão formar um médico que deverá ter postura ética, visão humanística, senso de responsabilidade social e compromisso com a cidadania.

O Conselho Federal de Medicina (CFM) deve ter o compromisso bastante claro com a formação médica. Se no passado pouco se fez para impedir a prolife-ração desenfreada de escolas médicas, demanda-se a responsabilidade de melhor formação ética de todos os egressos, evitando que o Código de Ética Médica vigente se transforme em um receituário, uma plataforma de punir e cassar simplesmente, em lugar de ter o propósito de formar melhor, preparar para um mundo de direitos amplos, universais, zelando pela autonomia do paciente, seu direito irrestrito de escolha.

Existem duas resoluções de 1975, do Conselho Federal de Medicina, que têm valor profético. A primeira determina aos médicos a supervisão dos procedimentos realizados por estudantes, dando conhecimento das implicações éticas de procedimentos e situações encontradas (Resolução CFM n. ${ }^{\circ}$ $663 / 75)$, a segunda recomenda a promoção de programas destinados ao ensino dos princípios da ética médica durante o período escolar (Resolução CFM n. ${ }^{\circ}$ 664/75). Ambas as resoluções foram apenas minimamente cumpridas ao longo das últimas décadas, principalmente no caso da última, que apenas na década de 1990, de forma incipiente, foram estabelecidos convênios dos Regionais com algumas escolas médicas. Porém, esforços têm sido feitos nos últimos anos pelo Conselho Federal de Medicina, em parceria com os Conselhos Regionais, para promover atualização dos médicos, oferecendo cursos para recém-formados ou médicos com escassas possibilidades de renovar o conhecimento, favorecendo discussões sobre temas recorrentes.

Cabe lembrar que no Brasil, para ser médico, exige-se um esforço cognitivo enorme, isto é, de memorização e raciocínio, mas não se faz qualquer exigência no plano moral, sendo que os diplomas de graduação, consequentemente, não atestam resultados morais. 8 Portanto, apenas pelo fato de se graduar em medicina não é garantia de atributos morais necessários para a boa prática médica. É possível que alguns jovens jamais lograrão esta prática, pois o "defeito" pode não residir no sistema, mas na sua própria personalidade avessa a princípios humanitários, reconhecendo-se tão somente a si 
como depositário de quaisquer esforços. Entretanto, uns quantos, seguramente a maioria, poderiam se beneficiar de uma formação ética e bioética, repercutindo suas ações em favor dos pacientes e da sociedade como um todo. Para estes, o Código de Ética Médica não seria impeditivo de suas ações, mas orientador, estímulo para lograr a consecução de princípios que deveriam nortear a vida das pessoas, independente da área de atuação, mas, sobretudo, no âmbito da saúde, quando as pessoas se mostram mais vulneráveis.

Finalmente, a preocupação neste artigo foi mostrar como perfilou a necessidade de regulamentação da profissão médica, e como isso demandou códigos específicos, que foram na maior parte das vezes dirigidos a coibir comportamentos dos médicos, sem qualquer preocupação com a pessoa do profissional ou, ainda mais grave, sem uma visão humanitária do paciente, favorecendo seu bem-estar e melhores condições sociais de vida. É certo que algumas escolas médicas têm se esforçado em oferecer melhor formação técnica aos seus acadêmicos, mas o academicismo empurra o raciocínio clínico unicamente na direção dos avanços científicotecnológicos, esquecendo-se de burilar o caráter do futuro médico com a formação humanística. A frase marcante, atribuída a D. José Letamendi, catalão pensador da Medicina, parece adequada aqui: "O médico que só sabe medicina, nada sabe de medicina".

\section{Referências}

1. Alves JA. Éthos/êthos, o ser e o dever. O desenvolvimento de um conflito. J Ciências Cognitivas [periódico online]. 2007 [acesso em: 13 abr 2010]. Disponível em: http://jcienciascognitivas.home.sapo.pt/07-04_alves.html

2. Conselho Federal de Medicina (CFM). Código de Ética Médica: Resolução CFM n ${ }^{\circ}$ 1931, de 17 de setembro de 2009. Brasília, DF; 2009.

3. Pellegrino ED. Ethics and the moment of clinical truth. J Am Med Assoc. 1978; 239: 960-1.

4. Micheli A. En torno a las raices de la etica medica. Arch Inst Cardiol México. 1994; 64: 577-82.

5. Silva RM. A moralidade da relação médico-paciente. Cad CREMEB. 1996; 5: 9-49.

6. Potter VR. Bioethics: Bridge to the future. Englewood Cliffs: Prandice-Hall; 1971.

7. Rezende JM. Caminhos da medicina: O juramento de Hipócrates. Rev Paraense Med. 2003; 17: 38-47.

8. Massud M, Barbosa G. A profissão médica e o ser médico. In: A Saúde dos médicos do Brasil. Brasília: Conselho Federal de Medicina; 2007.

9. Assad JE. Relação médico-paciente no final do século XX. In: Desafios Éticos. Brasília: Conselho Federal de Medicina; 1993.

10. D’Avila RL. O comportamento ético-profissional dos médicos de Santa Catarina: uma análise dos processos disciplinares no período de 1958 a 1996 [dissertação]. Florianópolis: Universidade Federal de Santa Catarina; 1998.

11. Nunes R. Bioética e deontologia profissional. Colectânea bioética hoje - IV. Coimbra: Gráfica Coimbra; 2002.

12. D’Avila RL. É possível ensinar ética médica em um curso formal curricular? Rev Bioética. 2002; 10: 115-26.

13. Grisard N. Ética médica e bioética: A disciplina em falta na graduação. Rev Bioética. 2002; 10: 97-114.

14. Auby JM. O Estado e a profissão médica. Rev Bioética. 1996; 4: 71-7.

15. Moraes NC. Erro médico: Aspectos jurídicos. Rev Bras Cir Cardiovasc. 1996; 11: 55-9.

16. Falcão MSSA. A ética médica e suas infrações: um estudo sobre os processos ético-profissionais do Estado do Rio de Janeiro [dissertação]. Rio de Janeiro: Fundação Oswaldo Cruz; 1994.

17. Porto JA. O erro médico. Bol Acad Nac Med. 1990/1991; 151: 43-50.

18. Grisard N. Manual de orientação ética e disciplinar. 3 ed. Florianópolis: CREMESC; 2003.

19. França R. Erro médico. HFA Publ Tec Cient. 1987; 2: 2735.

20. La Vara HEM. El médico ante el delito. Rev Mex Anestesiol. 1995; 18: 1-2.

21. Cervantes J. Iatrogenic injuries in surgery. Acta Chir Belg. 1996; 96: 242-244.

22. Drumond JGF. O "ethos" médico: A velha e a nova moral médica. Montes Claros: Unimontes; 2005.

23. Coutinho, A.B. A Propósito de Guilherme Piso. Discurso de Posse (22 de setembro de 1971). Anais da Academia Pernambucana de Medicina. Vol. 1. Recife, janeiro 71/dezembro 74.

24. Coutinho, A.B. História e Filosofia das Ciências. Série Textos Inéditos e Escolhidos. Editora Universitária da UFPE. Recife, 1995.

25. Pereira Neto A. Primeiro código de ética médica (1931) algumas considerações. Bol CREMERJ. 1992; 37.

26. Kriger Filho DA. Comentários ao código de processo éticoprofissional médico. Porto Alegre: Editora Síntese; 1997.

27. Martin LM. A ética médica diante do paciente terminal. São Paulo: Editora Santuário Aparecida; 1993.

28. Péres H. Conselhos de Medicina. Origens, evolução e finalidades. In: Ética médica. Rio de Janeiro: CREMEG; 1974.

29. Conselho Federal de Medicina. Código de Ética Médica. Brasília, DF; 2010. 
30. D’Avila RL. O Conselho Federal de Medicina e o ensino da ética e bioética. Rev Bioética; 2003; 11: 51-6.

31. Gomes JCM. O atual ensino da ética para os profissionais de saúde e seus reflexos no cotidiano do povo brasileiro. Rev Bioética; 1996; 4: 53-64.

32. Meira AR, Cunha MMSC. O ensino da ética médica em nível de graduação nas faculdades de medicina do Brasil. Rev Bras Educ Med. 1994; 18: 1-48.

Recebido em 28 de julho de 2010

Versão final apresentada em 19 de outubro de 2010

Aprovado em 22 de novembro de 2010
33. Comissão Interinstitucional Nacional de Avaliação do Ensino Médico (CINAEM). Avaliação do ensino médico no Brasil - Relatório geral (1991 - 1997). Brasília, DF; 1997. 